\title{
Diverse characters of Brennan's paw incision model regarding certain parameters in the rat
}

\author{
Rahul Kumar, Shivani Gupta, Mayank Gautam, Saroj Kaler Jhajhria, and Subrata Basu Ray \\ Department of Anatomy, All India Institute of Medical Sciences, New Delhi, India
}

\begin{abstract}
Background: Brennan's rodent paw incision model has been extensively used for understanding mechanisms underlying postoperative pain in humans. However, alterations of physiological parameters like blood pressure and heart rate, or even feeding and drinking patterns after the incision have not been documented as yet. Moreover, though eicosanoids like prostaglandins and leukotrienes contribute to inflammation, tissue levels of these inflammatory mediators have never been studied. This work further investigates the antinociceptive effect of protein $\mathrm{C}$ after intra-wound administration.
\end{abstract}

Methods: Separate groups of Sprague-Dawley rats were used for quantitation of cyclooxygenase (COX) activity and leukotriene B4 level by enzyme-linked immunosorbent assay, as well as estimation of cardiovascular parameters and feeding and drinking behavior after paw incision. In the next part, rats were subjected to incision and $10 \mu \mathrm{g}$ of protein $\mathrm{C}$ was locally administered by a micropipette. Both evoked and non-evoked pain parameters were then estimated.

Results: COX, particularly COX-2 activity and leukotriene B4 levels increased after incision. Hemodynamic parameters were normal. Feeding and drinking were affected on days 1 and 3, and on day 1 , respectively. Protein $\mathrm{C}$ attenuated non-evoked pain behavior alone up to day 2 .

Conclusions: Based upon current observations, Brennan's rodent paw incision model appears to exhibit a prolonged period of nociception similar to that after surgery, with minimal interference of physiological parameters. Protein C, which is likely converted to activated protein $\mathrm{C}$ in the wound, attenuated the guarding score, which probably represents pain at rest after surgery in humans. (Korean J Pain 2019; 32: 168-77)

Key Words: Blood Pressure; Eicosanoids; Heart Rate; Inflammation; Nociception; Pain, Postoperative; Protein C; Rats; Wounds and Injuries.

Received December 27, 2018. Revised March 6, 2019. Accepted March 12, 2019.

Correspondence to: Subrata Basu Ray

Department of Anatomy, All India Institute of Medical Sciences, Sri Aurobindo Marg, Ansari Nagar, New Delhi 110029, India

Tel: +91-96-54994296, Fax: +91-11-26588641, E-mail: raysb48@gmail.com

ORCID: https://orcid.org/0000-0002-1776-1055

(a) This is an open-access article distributed under the terms of the Creative Commons Attribution Non-Commercial License (http:// creativecommons.org/licenses/by-nc/4.0/), which permits unrestricted non-commercial use, distribution, and reproduction in any medium, provided the original work is properly cited.

(c) The Korean Pain Society, 2019 


\section{INTRODUCTION}

Arachidonic acid derivatives like prostaglandins (PGs) and leukotrienes (LTs) are important mediators of inflammation [1]. These are synthesized by the cyclooxygenase (COX) and 5-lipoxygenase (5-LOX) enzymes respectively. COX has two isoforms: COX-1 (constitutive) and COX-2 (inducible). The latter is supposedly the main source of PGs during an inflammatory response [2]. Compared to LTs, which increase vascular permeability and promote infiltration by neutrophils, PGs produce vasodilation and also sensitize primary sensory afferents leading to pain $[1,3]$. Traditional nonsteroidal anti-inflammatory agents inhibit COX activity and thereby produce relief of pain.

Pain can occur spontaneously after tissue injury. It can also be evoked by non-noxious stimuli like light touch (allodynia) or to an exaggerated extent by mildly noxious stimuli (hyperalgesia). In the widely used rodent model of postoperative pain involving an incision in the paw, the non-evoked pain behavior (guarding) is relatively shortlasting (up to 3-4 days) in comparison to evoked behaviors which are present for a week or more [4]. Earlier studies have reported an increase in the levels of nerve growth factor [5], lactate [6], and interleukin (IL)-1 $\beta$ at the incision site [7].

However, the concentration of COX and LTs like leukotriene B4 (LTB4) are unknown after paw incision. Similarly, its effect on feeding and drinking behavior or on cardiovascular parameters has not been reported. Additionally, the antinociceptive effect of protein $\mathrm{C}$, an endogenous anti-inflammatory substance composed of a heavy and light peptide chains, was evaluated after intra-wound administration [8,9]. Previously, we had reported upon the anti-nociceptive effect of cannabinoid type 1 receptor agonist after direct intra-wound administration [10].

Protein $\mathrm{C}$ is present in the plasma as a precursor form and is mainly synthesized in the liver [11,12]. Following binding to the endothelial protein $\mathrm{C}$ receptor (EPCR), it is cleaved to its active form (activated protein $\mathrm{C}$ [APC] or APC) by thrombin [13]. Subsequently, APC, a serine protease enzyme, inactivates clotting factors Va and VIIla, thus acting as a natural anticoagulant [14]. When APC was locally administered to chronic pressure ulcers, growth of granulation tissue and epithelium was restored [15]. In tissue culture, APC promoted proliferation and migration of keratinocytes [16]. Apart from this, it has an anti-inflam- matory effect based upon suppression of nuclear factor-kappa B (NF-кB) [9,16-18], decreased release of cytokines like IL-6, and even inhibition of matrix metalloproteinase $9[18,19]$. Its anticoagulant and related anti-inflammatory effect have been harnessed for treating severe sepsis [17].

An antinociceptive effect of intravenously administered APC has been reported in neuropathic pain arising from C7 nerve compression [20]. Local treatment with the precursor form (protein C) also attenuated carrageenan-induced hyperalgesia [21]. However, its antinociceptive effect, if any, after local intra-wound administration, is unknown. We hypothesized that intra-wound APC would not only relieve pain by its anti-inflammatory effect but also promote early wound healing.

\section{MATERIALS AND METHODS}

\section{Animals}

Permission was obtained from the Institutional Animal Ethics Committee (695/IAEC/12;16/12/2013). Sprague-Dawley rats (male, weight about $250 \mathrm{~g}, \mathrm{n}=68$ ) were obtained from the animal facility of All India Institute of Medical Sciences, New Delhi, India. Animals were randomly distributed into various testing groups. Food and water were provided ad libitum. Optimum environmental conditions like temperature $\left(22^{\circ} \mathrm{C}-25^{\circ} \mathrm{C}\right)$ and light/dark cycles $(12 \mathrm{hr} / 12 \mathrm{hr})$ were maintained throughout the experimental period. All experimental procedures were conducted under the guidelines of International Association for the Study of Pain [22].

\section{Plantar incision}

The procedure of paw incision has been standardized earlier [23]. Under isoflurane anaesthesia, the plantar surface of the right paw was cleaned with povidone-iodine. A $1 \mathrm{~cm}$ long midline incision was made on the skin, starting onehalf inch from the proximal end of the heel. The underlying fascia and muscle were also incised. Subsequently, the wound was sutured with 4-0 nylon and knots were placed on the lateral side. Finally, the rat was transferred to a warm recovery chamber. Postincisional nociception by various behavioral tests was determined at specific time intervals after incision ( $2 \mathrm{hr}, 8 \mathrm{hr}$, and every $24 \mathrm{hr}$ up to day $7)$. The suture was removed on day 2 . 


\section{Intra-wound drug administration}

Lyophilised Protein C (P2200-1 mg; Sigma-Aldrich, St. Louis, MO) was dissolved in physiological saline at a concentration of $10 \mu \mathrm{g} / 10 \mu \mathrm{L}$. Protein C $10 \mu \mathrm{g}$ was administered into the wound using a sterile micropipette just before suturing, and left undisturbed for 30 seconds (Fig. 1). Prior to this, skin edges were pulled up by forceps to form a pocket in order to prevent loss of the drug [10]. The drug was administered only once during the entire experimental procedure. The control group received saline.

\section{Assay of COX activity}

The assay of COX activity was only determined in the control group. Animals were euthanized by inhalation of carbon dioxide. Skin and muscle tissue from the site of incision (a 5-6 mm block of tissue around the incision site) were isolated by a scalpel blade. The tissue samples $(n=4)$ at each time point (basal and post-incision $2 \mathrm{hr}, 8 \mathrm{hr}$, as well as days 1 and 3) were pooled and then processed, using a COX activity kit as per manufacturer's instructions (Cat. No. 760151; Cayman Chemicals, Ann Arbor, MI) to determine total COX along with the activity of $\mathrm{COX}-1$ and COX -2 individually. The test was carried out in a 96 well enzyme-linked immunosorbent assay (ELISA) microplate. Absorbance was taken at $590 \mathrm{~nm}$ using an ELISA plate reader (iMark ${ }^{\mathrm{TM}}$ Microplate Absorbance reader; Bio-Rad

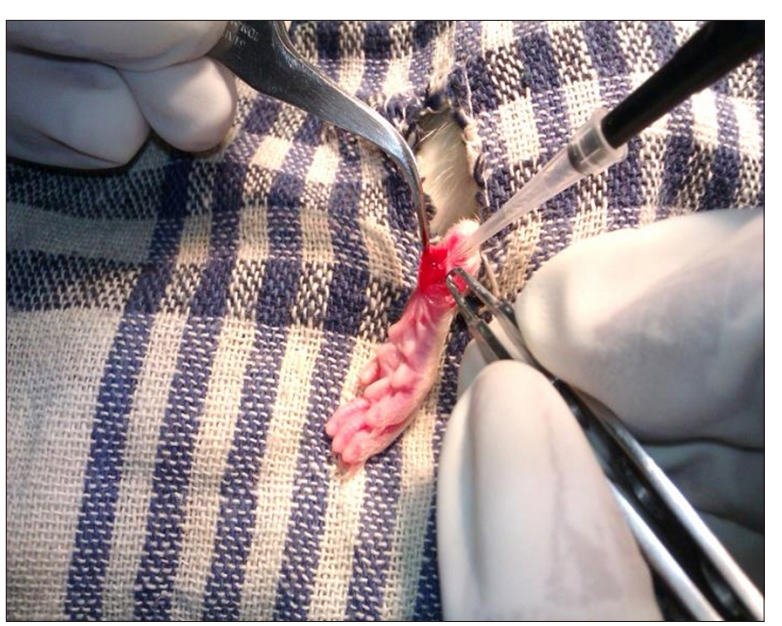

Fig. 1. Activated protein $C(10 \mu \mathrm{g})$ was administered by intra-wound route using a sterile micropipette, only once in each rat during the experiment.
Laboratories, Hercules, CA). Final activity was measured in $\mathrm{nM} / \mathrm{min} / \mathrm{mL}(\mathrm{U} / \mathrm{mL})$.

\section{Estimation of LTB4}

The procedure of the collection of paw tissue was the same as for the estimation of COX activity. Again, it was only evaluated in the control group. However, tissue samples were not required to be pooled. The concentration of LTB4 was quantified by a competitive LTB4 ELISA kit (Cat. No. 520111; Cayman Chemicals) as per manufacturer's instructions. Absorbance was taken at $420 \mathrm{~nm}$ (iMark ${ }^{\mathrm{TM}}$ Microplate Absorbance reader; Bio-Rad Laboratories). The final concentration was expressed in $\mathrm{pg} / \mathrm{mL}$.

\section{Assessment of cardiovascular parameters}

The non-invasive component detection analysis tail-cuff system was used to measure heart rate and blood pressure (Kent Scientific Corporation, Torrington, CT) [24]. Only the control group was used for this study. This system uses volume pressure recording to measure the flow of the blood in the tail. One day prior to the experiment, rats $(n=6)$ were put in restrainers with darkened nose cones in a warm environment for 30 minutes. This was done twice during the day. Two cuffs were put on the tail, an occlusion and a volume-pressure recording cuff, on the day of recording. Values of blood pressure (systolic and diastolic) and heart rate were displayed in the accompanying software. Readings were taken under basal condition and at 2 hours and days 1,3 , and 5 after incision (1,000-1,200 hr). The rats were housed individually. The average invasive systolic and diastolic blood pressure in the caudal venous artery is 95.9 $\pm 12.9 \mathrm{mmHg}$ and $73 \pm 13.7 \mathrm{mmHg}$, respectively, whereas the mean heart rate is 305 beats/min [25].

\section{Food and water consumption}

Each animal $(\mathrm{n}=6)$ belonging to the control group was habituated in individual cages for 2 days to note their average intake of food and water. Standard food pellets (50 g) were weighed in an electronic balance and kept daily in the food dispenser of the cage. The dispenser was closed from the outside to prevent extraneous loss. The remains of the food pellets at the bottom of the cage were collected every day and weighed along with the remaining 
pellets. Also, $100 \mathrm{~mL}$ of water was provided. The daily consumption of food and water was assessed every 24 hours for 7 days following the incision.

\section{Behavioral assays for nociception}

This was performed before (basal) and at specific time intervals after incision $(2 \mathrm{hr}, 8 \mathrm{hr}$, and days $1-4$ for guarding and days 1-7 for evoked pain behavior) by the same observer. The observer was blinded to the drugs administered to the animals.

\section{Guarding behaviour}

According to an earlier described protocol, rats were kept on a wire mesh platform (wire mesh with an $8 \times 8 \mathrm{~mm}$ pore size) and covered with plastic $(16 \times 16 \times 16 \mathrm{~cm})$ enclosures [26]. The acclimatization period was 30 minutes. Thereafter, the position of the hind paws was observed for one hour. This time was divided into 12 periods of $5 \mathrm{mi}-$ nutes each. During the first minute of each 5 minutes period, scores were given based upon the following: paw completely off the mesh $=2$; paw lightly resting on the mesh without weight bearing $=1$; and paw firmly on the mesh $=0$. Finally, the total scores were added for each paw and the score of the normal paw was deducted from the incised paw to obtain the cumulative pain score. Scores were between -24 and +24 , with lower scores indicating less nociception. The guarding score was determined in the basal condition, as well as at 2 and 8 hours after paw incision and then every 24 hours until day 4 .

\section{Mechanical allodynia}

Mechanical allodynia was determined by the sequential administration of von Frey filaments (North Coast Medical Inc., San Jose, CA) according to the "Up-down method" [27]. Von Frey filaments of different sizes (3.61, 3.84, 4.08, $4.31,4.56,4.74,4.93$, and 5.18) were applied for $7-8 \mathrm{sec}^{-}$ onds to the paw in a perpendicular manner from below the mesh. The filament exerts a pre-defined amount of pressure varying between 0.4 and $15 \mathrm{~g}$. Normally the animals are able to bear the maximum pressure $(15 \mathrm{~g})$, but after incision, mechanical hypersensitivity was manifested as paw withdrawal. An interval of 2 minutes was maintained between two consecutive applications. The value of me- chanical allodynia was expressed as a 50\% withdrawal threshold (g). Allodynia was determined under the basal condition, 2 and 8 hours after paw incision, and then every 24 hours until day 7 .

\section{Thermal hyperalgesia}

Thermal hyperalgesia was assessed by the Hargreaves method (Plantar Test apparatus; UGO Basile, Gemonio, Italy) [28]. It was evaluated just after allodynia. Rats were placed on a glass platform and covered by Perspex enclosures. Prior to recording, rats were allowed to acclimatize for 15 minutes. The source of radiant heat was kept beneath the platform and was manually directed towards the surgical site in the paw. The baseline latency period was between 8 and 10 seconds. The cut-off value was 20 seconds. Each rat was tested 3 times at intervals of $2 \mathrm{mi}^{-}$ nutes and the average of these values was used to calculate percent of maximum possible effect (\%MPE), which was derived as follows: (post drug latency - baseline latency) / (cut off latency-basal latency) $\times 100$.

\section{Statistical analysis}

Data were analysed by GraphPad Prism version 5 (GraphPad Software, San Diego, CA). Values are represented as mean \pm standard error of mean. Data was analysed by one-way analysis of variance followed by the Bonferroni multiple comparison test except for behavioral tests of nociception, which were assessed by two-way analysis of variance followed by the Bonferroni multiple comparison test. Values of COX activity could not be analysed as these were based upon the pooling of samples from 4 rats. A $P$ value of less than 0.05 was considered statistically significant.

\section{RESULTS}

\section{Estimation of COX activity}

Compared to basal levels (17.44 nM), total COX activity was consistently increased up to day 3 (Fig. 2). Maximum increase was noted at 8 hours $(61.01 \mathrm{nM})$. Between 2 hours and day $1, \operatorname{COX}-2$ activity was greater than COX-1 activity. Unexpectedly, under basal conditions, COX -2 activity (8.26 nM) was noted to be only slightly lower than COX-1 activity (9.18 nM). 


\section{Estimation of LTB4}

LTB4 concentration was relatively low under basal conditions (200.8 $\pm 51.63 \mathrm{pg} / \mathrm{mL}$ ) but increased by almost 5 fold at 8 hours $(1,043 \pm 153.2 \mathrm{pg} / \mathrm{mL})$ (Fig. 3). Thereafter, it remained at a higher level up to day 3.

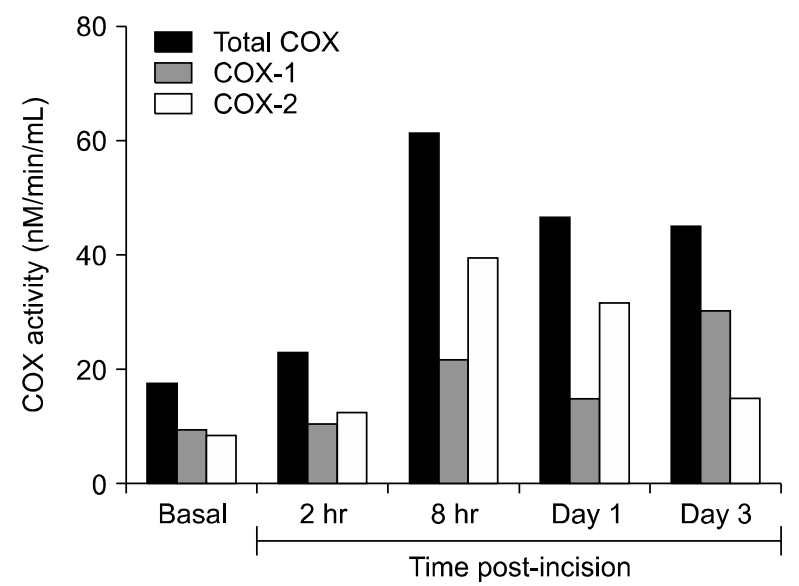

Fig. 2. Estimation of peroxidase component of cyclooxygenase (COX) enzymes by calorimetric method. Control animals $(n=4)$ were sacrificed, before (basal) and at specific time points after incision (between $2 \mathrm{hr}$ and day 3) for estimating COX activity. Maximum increase was noted at 8 hours, when COX-2 activity was greater than COX-1. Pooled tissues $(n=4)$ was evaluated at each time point and thus statistical analysis could not be performed.

A

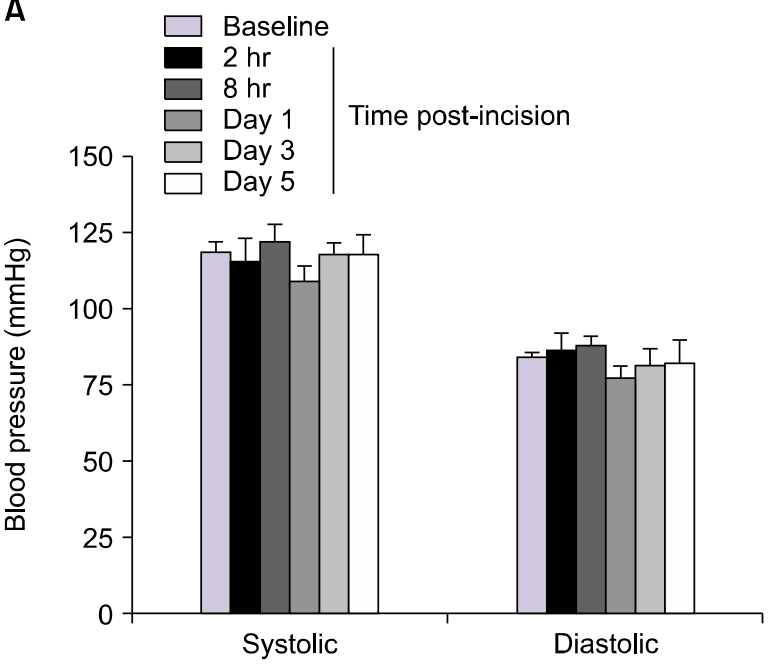

3. Blood pressure and heart rate

Hemodynamic parameters like blood pressure and heart rate were not significantly affected by the incision (Fig. 4). Basal values were $118 \pm 3.4 \mathrm{mmHg}$ and $83 \pm 2.7 \mathrm{mmHg}$ for systolic and diastolic blood pressure, respectively. Two

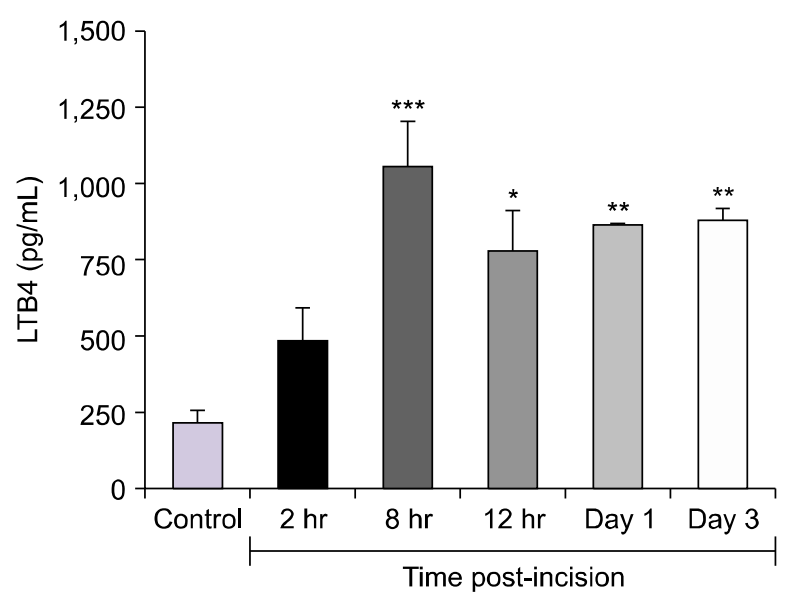

Fig. 3. Biochemical estimation of leukotriene B4 (LTB4) by competitive ELISA in control group of animals before (basal) and after incision (between $2 \mathrm{hr}$ and day 3). Maximum increase was observed at 8 hours compared to basal level. The increase persisted up to day 3 . Values $(n=4)$ are represented as mean \pm standard error of mean. ${ }^{\star} P<0.05$, ${ }^{\star \star} P<0.01,{ }^{\star \star *} P<0.001$.

B

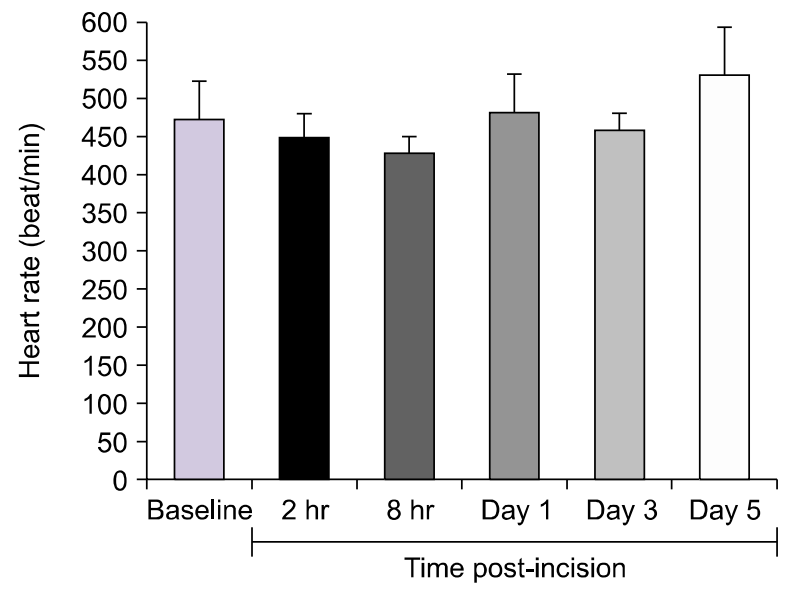

Fig. 4. Estimation of hemodynamic parameters in control group of animals, before (baseline) and after incision (between $2 \mathrm{hr}$ and day 5). Blood pressure (A) and heart rate (B) were not affected compared to baseline data. Values are expressed as mean \pm standard error of mean. $n=6$ at each time point. 
hours after, these were $115 \pm 7.6$ and $86 \pm 5.8 \mathrm{mmHg}$. The heart rate was $476 \pm 46$ beats/min and $449 \pm 32$ beats/min before and 2 hours after incision.

\section{Food and water consumption}

Food (pellets) (basal, $20.1 \pm 0.6 \mathrm{~g}$ vs. day $1,12.4 \pm 0.8 \mathrm{~g})$ and water (basal, $39.4 \pm 0.9 \mathrm{~mL}$ VS. day $1,31.4 \pm 0.9$ $\mathrm{mL}$ ) consumption were reduced 1 day after incision (Fig. 5). Food consumption decreased again on day 3 (16.6 $\pm 0.8 \mathrm{~g})$.

A

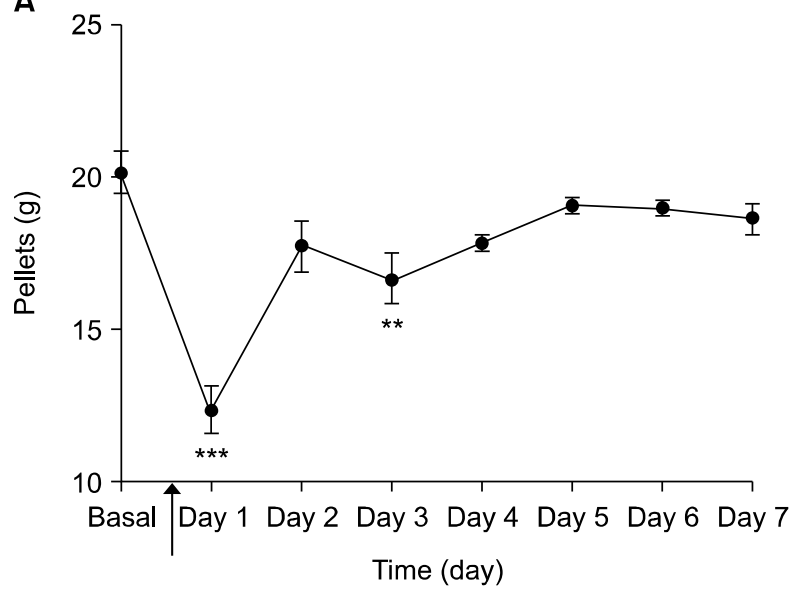

5. Nociceptive behaviour

All the three behavioral parameters demonstrated maximum nociception (highest values for cumulative pain score, $\% \mathrm{MPE}$, and lowest values for a 50\% withdrawal threshold) immediately after incision (Fig. 6). Among these, treatment with protein $\mathrm{C}$ once during the entire experiment, attenuated the cumulative pain score (Fig. 6A). This effect was observable up to day 2. Evoked pain behaviors were unaffected (Fig. 6B, C).

Fig. 5. Assessment of metabolic function in control animals. Time of incision is indicated (line arrow). Feeding behaviour was affected at days 1 and 3 (A) and drinking on day 1 (B) after incision. All values were compared to baseline intake. Values are represented as mean \pm standard error of mean. Food consumption was expressed as $\mathrm{g} /$ day. $\mathrm{n}=6$ at each time point. ${ }^{\star} P<0.05,{ }^{* \star} P<0.01,{ }^{\star \star *} P<0.001$.

A

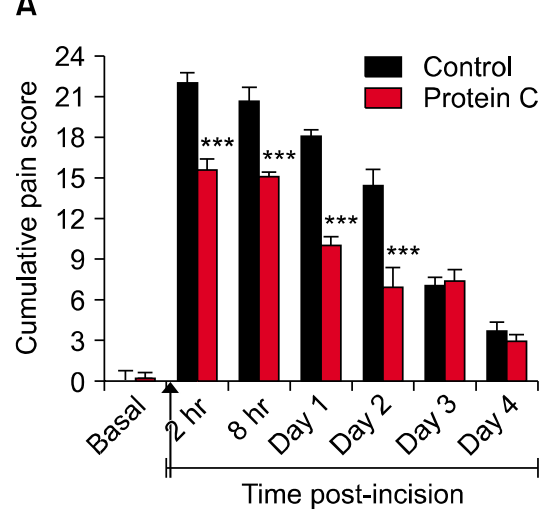

B

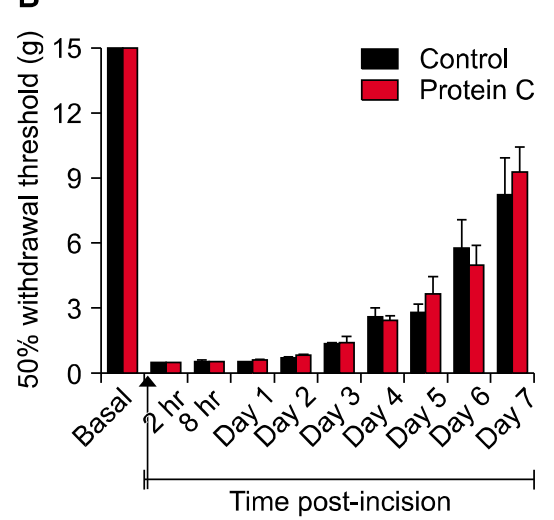

C

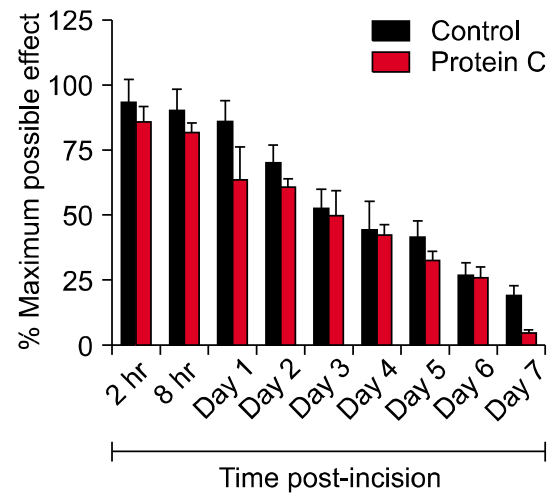

Fig. 6. Intra-wound administration of protein C (10 $\mu \mathrm{g})$ only once, resulted in a decrease in guarding score (A) but did not affect mechanical allodynia (B) or thermal hyperalgesia (C). Treatment with activated protein $\mathrm{C}$ reduced guarding score from 2 hours to day 2 in comparison to control group. Values $(n=6)$ are represented as mean \pm standard error of mean. Day 1 to 7 refers to days 1 to $7\left({ }^{* * *} P<0.001\right)$. 


\section{DISCUSSION}

Despite substantial advancement in the understanding of basic pain mechanisms, the incidence of postoperative pain remains high [29]. For example, a disease modifying strategy involving transplantation of embryonic tissue containing GABAergic inhibitory interneurons in the dorsal horn attenuated pain [30]. Also, severe pain during the postoperative period can be a risk factor for chronic postoperative pain [31]. An extensive study across several hospitals in Spain detected severe pain in $39.4 \%$ of patients following surgery [32].

Undoubtedly, experiments on the Brennan's rodent paw incision model have contributed significantly to the existing knowledge of postoperative pain $[4,33]$. In the present work, certain patho-physiological parameters were evaluated in this murine model. Estimation of COX enzymes (also known as PG endoperoxidase $\mathrm{H}$ synthases 1 and 2) at the incision site revealed the trend of increasing activity of COX-2 enzyme during the acute phase of postincisional nociception. This was consistent with the induction of COX-2 activity during inflammation $[2,34]$, though COX -1 is involved in controlling physiological processes in the basal condition [35].

In an earlier study, which had used immunohistochemistry and Western blot to analyse relative proportions of COX enzymes following skin injury in rats, COX-2, when compared to $\mathrm{COX}-1$, started increasing by 12 hours and peaked at 3 days [36]. In the current study, COX-2 activity peaked at 8 hours and also showed higher levels than COX-1. Along with COX, LTB4 levels also increased as has been reported previously in other instances [37,38]. Recently, LTB4 has been reported to prolong inflammation and delay wound healing [39].

The postoperative period is a crucial one for both the patient and the anesthesiologist. Monitoring of vital $\mathrm{pa}^{-}$ rameters provides feedback regarding the well-being of the patient. Significant change in blood pressure or heart rate was absent after paw incision, which would otherwise affect the validity of the results obtained from this preclinical model. However, a temporary decrease of food and water intake was noted immediately after incision. This could be due to a robust nociceptive response at this time $[40,41]$.

Overall, the use of the rodent paw incision model as a preclinical model for studies on postoperative pain ap- pears justified. It minimally interferes with vital and other physiological parameters as the current results show, and provides an extended window of post-incisional nociception when putative antinociceptive drugs could be gainfully evaluated.

As hypothesized, protein $\mathrm{C}$, which was likely converted to APC by thrombin in the wound, specifically attenuated the guarding score without affecting other nociceptive parameters. A previous study has also documented a decrease in nociception after intra-plantar injection of protein C [21]. There are prominent differences between guarding and other nociceptive behaviors. In short, the former is non-evoked in nature and likely reflects pain, at rest, after surgery, and has a shorter duration and is readily amenable to treatment with low doses of morphine $[4,26,33]$.

Previously, intra-wound administration of cannabinoid agonist under identical experimental conditions also attenuated only the guarding score [10]. It is speculated that guarding behavior is predominantly mediated at the site of tissue injury whereas spinal cord mechanisms like central sensitization could underlie hyperalgesia and allodynia. For example, allodynia was correlated with internalization of the neurokinin type 1 receptor in the rat spinal cord [42].

Considering the low dose $(10 \mu \mathrm{g})$ of protein $\mathrm{C}$ used for the study, its antinociceptive effect was probably locally mediated. It crosses the blood-brain barrier but a centrally-mediated antinociceptive effect has not been reported as yet [43]. Its predominant mechanism of action is probably an anti-inflammatory effect linked to decreased inflammasome formation at the site of injury [44]. This follows binding of APC to the protease activated receptor 1 [45]. One of the signals for the formation of inflammasome is the activation of $\mathrm{NF}-\kappa \mathrm{B}$, and this is inhibited by APC [9,18-19]. Synthesis of matrix metalloproteinase 9, a pro-inflammatory molecule, is reduced by APC and this action is mediated by blockade of the $\mathrm{NF}-\kappa \mathrm{B}$ and p38 mitogen-activated protein kinase [19].

APC can also bind to monocytes, which express the EPCR [46]. Since APC possesses anti-coagulant properties, the wound was observed for 24-48 hours for any bleeding episode. There was none, either in the preliminary experiments for determination of the test dose of APC ( $\mathrm{n}$ = 3; data not shown) or subsequently. Importantly, the normal protein $\mathrm{C}$ level in human plasma is $4.8 \pm 1.0$ $\mu \mathrm{g} / \mathrm{mL}$ [47]. No other obvious side effects were observed. 
Healing, which was similar to the control group, was evaluated by physical examination of the wound. However, a detailed histopathological examination could not be done. Protein $\mathrm{C}$, which was used in the current experiment, was derived from human plasma. Thus, toxicity studies were not done.

In conclusion, the results show for the first time that haemodynamic parameters remain unchanged after paw incision in the Brennan's model, whereas feeding patterns are temporarily disturbed to a slight extent. It was important to quantify these, because major alterations could affect the validity of studies conducted on this rodent model. Both COX, particularly COX-2, and 5-LOX activity (as evident from increased levels of LTs) increased after paw incision. Intra-wound protein $\mathrm{C}$, an endogenous bioactive molecule, could significantly suppress a specific parameter of post-incisional nociception, which has been considered to be equivalent to pain at rest after surgery $[4,24,33]$. This effect, which is likely due to its conversion to APC, could be the result of its proposed anti-inflammatory effect $[9,16-19]$. This information could have clinical significance.

\section{ACKNOWLEDGMENTS}

Financial support was provided by the Department of Biotechnology, as well as the Ministry of Science and Technology, Government of India (BT/PR1434/Med/30/504/2010 dated 5-1-2011).

\section{CONFLICT OF INTETEST}

No potential conflict of interest relevant to this article was reported.

\section{ORCID}

Rahul Kumar, https://orcid.org/0000-0003-4639-3113

Shivani Gupta, https://orcid.org/0000-0002-3375-2239

Mayank Gautam, https://orcid.org/0000-0002-7257-5837

Saroj Kaler Jhajhria,

https://orcid.org/0000-0002-9448-0687

Subrata Basu Ray, https://orcid.org/0000-0002-1776-1055

\section{REFERENCES}

1. Kumar V, Abbas AK, Aster JC. Robbins basic pathology. Philadelphia, Elsevier. 2013, pp 29-73.

2. Dubois RN, Abramson SB, Crofford L, Gupta RA, Simon LS, Van De Putte LB, et al. Cyclooxygenase in biology and disease. FASEB J 1998; 12: 1063-73.

3. Funk CD. Prostaglandins and leukotrienes: advances in eicosanoid biology. Science 2001; 294: 1871-5.

4. Xu J, Brennan TJ. The pathophysiology of acute pain: animal models. Curr Opin Anaesthesiol 2011; 24: 508-14.

5. Wu C, Boustany L, Liang H, Brennan TJ. Nerve growth factor expression after plantar incision in the rat. Anesthesiology 2007; 107: 128-35.

6. Kim TJ, Freml L, Park SS, Brennan TJ. Lactate concentrations in incisions indicate ischemic-like conditions may contribute to postoperative pain. J Pain 2007; 8: 59-66.

7. Gautam M, Prasoon P, Kumar R, Reeta KH, Kaler S, Ray SB. Role of neurokinin type 1 receptor in nociception at the periphery and the spinal level in the rat. Spinal Cord 2016; 54: 172-82.

8. Foster D, Davie EW. Characterization of a cDNA coding for human protein C. Proc Natl Acad Sci U S A 1984; 81: 4766-70.

9. Joyce DE, Gelbert L, Ciaccia A, DeHoff B, Grinnell BW. Gene expression profile of antithrombotic protein $\mathrm{C}$ defines new mechanisms modulating inflammation and apoptosis. J Biol Chem 2001; 276: 11199-203.

10. Kumar R, Prasoon P, Gautam M, Ray SB. Comparative antinociceptive effect of arachidonylcyclopropylamide, a cannabinoid 1 receptor agonist \& lignocaine, a local anaesthetic agent, following direct intrawound administration in rats. Indian J Med Res 2016; 144: 730-40.

11. Bauer KA, Kass BL, Beeler DL, Rosenberg RD. Detection of protein C activation in humans. J Clin Invest 1984; 74 : 2033-41.

12. Long GL, Belagaje RM, MacGillivray RT. Cloning and sequencing of liver CDNA coding for bovine protein C. Proc Nat Acad Sci U S A 1984; 81: 5653-6.

13. Esmon CT. The endothelial cell protein $\mathrm{C}$ receptor. Thromb Haemost 2000; 83: 639-43.

14. Marlar RA, Kleiss AJ, Griffin JH. Mechanism of action of human activated protein $\mathrm{C}$, a thrombin-dependent anticoagulant enzyme. Blood 1982; 59: 1067-72.

15. Wijewardena A, Lajevardi SS, Vandervord E, Vandervord J, Lang TC, Fulcher $G$, et al. Activated protein $C$ to heal pressure ulcers. Int Wound J 2016; 13: 986-91.

16. Xue M, Thompson P, Kelso I, Jackson C. Activated protein C stimulates proliferation, migration and wound closure, inhibits apoptosis and upregulates MMP-2 activity in cultured human keratinocytes. Exp Cell Res 2004; 299: 119-27.

17. Bernard GR, Vincent JL, Laterre PF, LaRosa SP, Dhainaut 
JF, Lopez-Rodriguez A, et al. Efficacy and safety of recombinant human activated protein $\mathrm{C}$ for severe sepsis. $\mathrm{N}$ Engl J Med 2001; 344: 699-709.

18. Yuksel M, Okajima K, Uchiba M, Horiuchi S, Okabe $H$. Activated protein $\mathrm{C}$ inhibits lipopolysaccharide-induced tumor necrosis factor-alpha production by inhibiting activation of both nuclear factor-kappa B and activator protein-1 in human monocytes. Thromb Haemost 2002; 88: 267-73.

19. Xue M, March L, Sambrook PN, Jackson CJ. Differential regulation of matrix metalloproteinase 2 and matrix metalloproteinase 9 by activated protein C: relevance to inflammation in rheumatoid arthritis. Arthritis Rheum 2007; 56: 2864-74.

20. Smith JR, Galie PA, Slochower DR, Weisshaar CL, Janmey PA, Winkelstein BA. Salmon-derived thrombin inhibits development of chronic pain through an endothelial barrier protective mechanism dependent on APC. Biomaterials 2016; 80: 96-105.

21. Pichler L, Schramm W, Ulrich W, Varadi K, Schwarz HP. Antinociceptive properties of protein $C$ in a model of inflammatory hyperalgesia in rats. Thromb Haemost 1995; 73 : 252-5.

22. Zimmermann M. Ethical guidelines for investigations of experimental pain in conscious animals. Pain 1983; 16: 10910.

23. Brennan TJ, Vandermeulen EP, Gebhart GF. Characterization of a rat model of incisional pain. Pain 1996; 64: 493-501.

24. Brown C, McFarlane-Anderson N, Alexander-Lindo R, Bishop K, Dasgupta T, McGrowder D. The effects of S-nitrosoglutathione and S-nitroso-N-acetyl-D, L-penicillamine in a rat model of pre-eclampsia. J Nat Sci Biol Med 2013; 4: 3305.

25. Wang $Y$, Cong Y, Li J, Li X, Li B, Qi S. Comparison of invasive blood pressure measurements from the caudal ventral artery and the femoral artery in male adult SD and Wistar rats. PLoS One 2013; 8: e60625.

26. Spofford CM, Ashmawi H, Subieta A, Buevich F, Moses A, Baker M, et al. Ketoprofen produces modality-specific inhibition of pain behaviors in rats after plantar incision. Anesth Analg 2009; 109: 1992-9.

27. Chaplan SR, Bach FW, Pogrel JW, Chung JM, Yaksh TL. Quantitative assessment of tactile allodynia in the rat paw. J Neurosci Methods 1994; 53: 55-63.

28. Hargreaves K, Dubner R, Brown F, Flores C, Joris J. A new and sensitive method for measuring thermal nociception in cutaneous hyperalgesia. Pain 1988; 32: 77-88.

29. Pogatzki-Zahn EM, Segelcke D, Schug SA. Postoperative pain-from mechanisms to treatment. Pain Rep 2017; 2: e588.

30. Braz JM, Etlin A, Juarez-Salinas D, Llewellyn-Smith IJ, Basbaum Al. Rebuilding CNS inhibitory circuits to control chronic neuropathic pain and itch. Prog Brain Res 2017;
231: $87-105$

31. Lavand'homme P, Wu C, Katz J. From acute to chronic postoperative pain. In: Pain 2018: refresher courses for the 17th World Congress on Pain. Edited by Gold MS, PogatzkiZahn EM, Wallace MS. Washington, IASP Press. 2018, pp 147-57.

32. Polanco-García M, García-Lopez J, Fàbregas N, Meissner W. Puig MM; PAIN-OUT-Spain Consortium. Postoperative pain management in Spanish hospitals: a cohort study using the pain-out registry. J Pain 2017; 18: 1237-52.

33. Brennan TJ. Pathophysiology of postoperative pain. Pain 2011; 152(3 Suppl): S33-40.

34. Rouzer CA, Marnett LJ. Cyclooxygenases: structural and functional insights. J Lipid Res 2009; 50 Suppl: S29-34.

35. Smith WL, DeWitt DL, Garavito RM. Cyclooxygenases: structural, cellular, and molecular biology. Annu Rev Biochem 2000; 69: 145-82.

36. Futagami A, Ishizaki M, Fukuda Y, Kawana S, Yamanaka N. Wound healing involves induction of cyclooxygenase-2 expression in rat skin. Lab Invest 2002; 82: 1503-13.

37. Köller M, König W, Brom J, Raulf M, Gross-Weege W, Erbs $G$, et al. Generation of leukotrienes from human polymorphonuclear granulocytes of severely burned patients. J Trauma 1988; 28: 733-40.

38. Cunha JM, Sachs D, Canetti CA, Poole S, Ferreira SH, Cunha $F Q$. The critical role of leukotriene B4 in antigen-induced mechanical hyperalgesia in immunised rats. $\mathrm{Br} \mathrm{J}$ Pharmacol 2003; 139: 1135-45.

39. Guimarães FR, Sales-Campos H, Nardini V, da Costa TA, Fonseca MTC, Júnior VR, et al. The inhibition of 5-Lipoxygenase (5-LO) products leukotriene B4 (LTB $\mathrm{LT}_{4}$ and cysteinyl leukotrienes (cysLTS) modulates the inflammatory response and improves cutaneous wound healing. Clin Immunol 2018; 190: 74-83.

40. Foo H, Crabtree $K$, Thrasher A, Mason P. Eating is a protected behavior even in the face of persistent pain in male rats. Physiol Behav 2009; 97: 426-9.

41. Hackett AF, Yeung CK, Hill GL. Eating patterns in patients recovering from major surgery--a study of voluntary food intake and energy balance. Br J Surg 1979; 66: 415-8.

42. Fujita M, Fukuda T, Sato Y, Takasusuki T, Tanaka M. Allopregnanolone suppresses mechanical allodynia and internalization of neurokinin-1 receptors at the spinal dorsal horn in a rat postoperative pain model. Korean $\mathrm{J}$ Pain 2018; 31 : $10-5$.

43. Deane R, LaRue B, Sagare AP, Castellino FJ, Zhong Z, Zlokovic BV. Endothelial protein C receptor-assisted transport of activated protein $C$ across the mouse blood-brain barrier. J Cereb Blood Flow Metab 2009; 29: 25-33.

44. Carney EF. Inflammation: activated protein C inhibits inflammasome activation in IRI. Nat Rev Nephrol 2017; 13: 662.

45. Riewald M, Petrovan RJ, Donner A, Ruf W. Activated protein 
C signals through the thrombin receptor PAR1 in endothelial cells. J Endotoxin Res 2003; 9: 317-21.

46. Toltt LJ, Austin RC, Liaw PC. Activated protein C modulates inflammation, apoptosis and tissue factor procoagulant activity by regulating endoplasmic reticulum calcium depletion in blood monocytes. J Thromb Haemost 2011; 9: 582-92.

47. Comp PC, Nixon RR, Esmon CT. Determination of functional levels of protein $\mathrm{C}$, an antithrombotic protein, using thrombinthrombomodulin complex. Blood 1984; 63: 15-21. 